\title{
ДУХОВНОСТЬ И РАЦИОНАЛЬНОСТЬ В СОВРЕМЕННОЙ КУЛЬТУРЕ
}

\section{В.С. Писчиков, М.М. Холин}

Судьбы рациональности и духовности в современной культуре, несмотря на различия, существующие между ними, во многом сходны: теряя позиции под натиском наступательно-агрессивной, далеко не всегда компетентной критики, они вынуждены отстаивать свое право на существование, доказывая свою состоятельность и востребованность. Их нынешнее положение в обществе нередко и, на наш взгляд, вполне справедливо характеризуется одинаково - как кризисное. Является ли этот кризис только следствием и выражением общего кризиса современной духовной культуры или обусловлен прежде всего своими, особенными причинами - вопрос неоднозначный и дискуссионный. Бесспорно одно: ситуация кризиса рациональности и духовности объективно поставила исследователей в условия, когда они вынуждены поновому взглянуть на природу этих феноменов, их взаимосвязь и место в бытии современного общества и человека.

При этом если духовность, независимо от ее истолкований, всегда понималась как ценность культуры, то аналогичное восприятие рациональности - скорее следствие социокультурной ситуации, в которой она пребывает сейчас. Еще одним следствием осмысления кризисного положения рациональности и духовности является то, что доминировавшая длительное время в философских исследованиях тенденция их разведения и противопоставления постепенно уступает место стремлению выявить их внутреннее единство и родство как важнейших ценностей современной культуры. В русле именно этой, на наш взгляд, наиболее плодотворной эвристически и актуальной в социокультурном отношении позиции в статье и будет идти речь о характере взаимосвя-

Актуальні проблеми духовності

(Відп. ред.: Я.В. Шрамко)

Кривий Ріг (2007), 3-15 
зи рациональности и духовности.

Методологическим основанием противопоставления духовности и рациональности является неокантианская идея жесткого разграничения наук о природе и наук о духе, как якобы противоположных полюсов культуры. Питательной почвой и опорой этой тенденции был имевший сильное влияние в культуре второй половины XIX - первой половине XX столетий сциентизм. Кризис же сциентистской парадигмы, усиление, а затем и динамичное наступление по всем азимутам культуры антисциентизма со всей очевидностью продемонстрировали узость и односторонность сциентистского понимания рациональности. Однако при этом выявилась также несостоятельность в интерпретации духовности и рациональности и противоположной-антисциентистской методологемы.

Справедливая критика антисциентизмом чрезмерных претензий научной рациональности вышла далеко за эти границы и стала все больше перерастать в тотальную критику рациональности вообще. Со временем обнаружилось и то, что эта критика опосредованно, а нередко и непосредственно, направлена также против основ подлинной духовности. Свою весомую лепту во все эти процессы, многократно усиливая и обостряя их, несомненно, внес и постмодернизм. В сложившемся социокультурном контексте стало выявляться все больше точек соприкосновения между рациональностью и духовностью как феноменами культуры.

Поскольку в существующей философской литературе спектр различий в интерпретации рациональности и духовности весьма широк, необходимо определиться в их истолковании. При этом мы не преследуем цели анализировать различные точки зрения по вопросу, а хотим лишь обратить внимание на крайности, которых попытаемся избежать в своем понимании рассматриваемых категорий.

Неприемлемо, на наш взгляд, истолкование духовности как синонима «духовное» («духовный мир», «духовная жизнь»). Примером такого понимания может быть позиция Барулина В.С.: «Духовность, пишет он, - включает в себя полноту, целостность, взаимосвязанность всех компонентов духовной жизни человека... Что же касается содержания духовных процессов: научных концепций, религиозных верований, эстетических категорий, обыденно-практических знаний и т. д., то оно также все, без малейшего исключения, объемлется духовностью человека» [2, с. 112]. Подобное представление о духовности уязвимо не только в том отношении, что не выявляет ее природы, но и, включая в ее содержание рациональность в полном объеме, снимает проблему их 
соотношения, которая, естественно, таким способом не разрешается.

Столь же неприемлемо и абсолютное противопоставление духовности рациональности, сведение духовности к сфере бессознательного, понимание ее как «духовного бессознательного»: «подлинное духовное в основе своей имеет бессознательную, точнее нерефлексивную природу... Следовательно, содержанием духовного мира личности является не столько сознание, рефлексия, сколько духовное бессознательное. Сознание - это всего лишь внешняя оболочка, форма», - полагает В.Н. Волков [4, с. 124]. Очевидно, что такая интерпретация духовности столь же мало, как и предыдущая, проясняет ее суть и, полностью выводя за ее пределы рациональность, субстанциально противопоставляет их.

Аналогичные названным выше крайности существуют и в интерпретации рациональности. Сциентистское сведение ее исключительно к научной рациональности, причем по преимуществу к естественнонаучной и логико-математической, ставит рациональность в жесткую оппозицию к духовности, делая бессмысленным поиск точек соприкосновения между ними. Однако не менее уязвимо и эвристически бесплодно и чрезмерно широкое понимание рациональности, фактически отождествляющее ее с дискурсом вообще. В таком случае рациональность теряет свои зримые очертания, позволяя включать даже в научную рациональность эзотерический дискурс. Это характерно, например, для П. Козловски: «Факт существования эзотерических форм мышления также и в науках свидетельствует о том, что на основании различных взглядов внутри научного сообества могут существовать более, чем один тип исследования» [10, с. 32]. Такое размывание границ рациональности также закрывает пути конструктивного обсуждения проблемы соотношения ее с духовностью.

Таким образом, представленные позиции, на наш взгляд, неадекватно выражают сущность и специфику духовности и рациональности, а это делает фактически невозможной их идентификацию. Не менее важно и то, что эти позиции не только не способствуют, но затрудняют выявление характера взаимоотношений между рациональностью и духовностью. Отмеченное и побуждает нас определиться в понимании рассматриваемых категорий.

Понятие духовности мы рассматриваем по преимуществу как аксиологическую категорию в отличие от близких к ней понятий «дух», «духовное», «духовный мир», «духовная жизнь». Духовность-это то в содержании духовного мира человека, что обладает нравственно-гуманистической интенцией, что ориентировано на высшие нематериаль- 
ные ценности бытия - добро, любовь, красоту, истину, свободу, справедливость. В зависимости от уровня и характера духовного развития личности ее духовный мир может в большей или меньшей степени обладать качеством духовности. Структурно духовность можно представить как систему духовных ценностей (убеждения, принципы, идеалы) и соответствующих им духовных потребностей и интересов, чувств, эмоций и переживаний. (Наше понимание духовности и его обоснование представлено в статьях, опубликованных в предыдущих выпусках настоящего издания. См.: Актуальні проблеми духовності. Вип. 2, 3, 4.-Кривий Ріг, 1995, 2000, 2002).

В понимании другого концептуального для данной статьи понятия рациональности мы будем исходить из концепции В.С. Швырева, наиболее полно представленной им в монографии «Рациональность как ценность культуры. Традиция и современность».- М., 2003, а также в фундаментальной коллективной монографии «Исторические типы рациональности». В двух томах. - М., 1995.

В качестве отправной точки в истолковании природы рациональности, как вполне обоснованно полагает В.С.Швырев, и в наше время могут оставаться классические представления о ней, сформированные в философии Нового времени и эпохи Просвещения. Исходя из этих представлений, рациональность можно определить как специфический способ освоения мира человеком, мыслительную и практическую деятельность, осуществляющуюся в соответствии с некоторыми правилами и нормами, которые могут быть выражены в общезначимой форме $[8$, т. 1]. Среди таких правил и норм особое значение имеют следование логическим законам мышления, ориентация на адекватность в постижении или освоении предмета, а также стремление к соответствию мысли и действия реальной действительности. По словам Швырева B.С., «специфика рациональной мысли в полноте самораскрытия ее конструктивного потенциала, взятого именно в аспекте ее ответственности за адекватное постижение ее предмета» [15, с. 37].

Различным эпохам в истории человечества, типам культуры и социумов, а также историческим этапам в их развитии соответствуют и свои типы рациональности. Исходя из этого основания, выделяют античный и средневековый, восточный и европейский, традиционный и современный, классический и неклассический типы рациональности. На уровне отдельного социума правомерно выделять типы рациональности, соответствующие формам общественного сознания - философский, научный, моральный, эстетический, правовой и др. В границах же каждого из названных типов также правомерно вычленять 
определенные виды рациональности. Например, внутри научной рациональности различают классическую, неклассическую и постнеклассическую рациональности, а внутри моральной-коллективистскую и индивидуалистическую рациональность. Однако принципиально важно отметить, что всем названным и другим типам и видам рациональности присущи одни и те же сущностные признаки.

Продуктивна и принципиально важна для нас идея В.С. Швырева о существовании «закрытого» и «открытого» типов рациональности, которые в определенной степени коррелируют соответственно с рассудком и разумом. «Закрытая» рациональность осуществляется внутри принятой сетки познавательных координат и является по своему характеру «некритически-оптимистической». Этот тип рациональности доминировал в классической культуре, включая и науку. «Открытая» рациональность, напротив, в своем осуществлении выходит за пределы фиксированной системы координат, являясь по своему характеру «критически-рефлексивной». Этот тип рациональности также зарождается уже в классической культуре, сосуществуя с «некритическиоптимистической» и оппонируя ей [15].

Открытая рациональность и становится источником неклассической, а затем превращается в доминирующий в современной культуре, прежде всего в науке, тип рациональности. В нем, однако, сохраняется характерная для классической, одна из ключевых в ней, «принципиальная реалистическая установка», которая здесь «существенным образом трансформируется. Она оказывается не просто интенцией на предмет познания «сам по себе», но, по возможности, наиболее точной рефлексивной фиксацией специфически той реальной позиции, в которой оказывается субъект в своем отношении к миру, в который он включен» $[15$, с. 136].

Проблему соотношения рациональности и духовности возможно корректно ставить и конструктивно обсуждать, лишь рассматривая их в контексте культуры в целом. Это предполагает подход к ним как двум взаимосвязанным атрибутам, составляющим культуры, которые одинаково необходимы для ее существования и развития. Названная установка уже сама по себе принципиально важна, так как предостерегает от необоснованного противопоставления духовности и рациональности. В таком понимании духовность предстает как ценностная составляющая культуры, а рациональность - прежде всего как ее интеллектуальная составляющая, различий между которыми не следует недооценивать: «При всех взаимоотношениях и духовное, и интеллектуальное начала должны оставаться в пределах своей «компетентно- 
сти». Иначе мы либо с когнитивных позиций будем трактовать духовность, либо с точки зрения духовности интерпретировать знания и тогда не сможем получить и адекватной характеристики ни их природы, ни их взаимодействия», - вполне обоснованно расставляет акценты В.Ж. Келле [9, с. 44].

Однако фиксируя отмеченное выше различие между духовностью и рациональностью, необходимо сразу же указать и на их родство, единство. Речь о том, что если «культура в целом представляет, в первую очередь, определенный комплекс информации» [12, с. 7], то и духовность как компонент культуры имеет информационный аспект: духовные ценности заключают в своем содержании определенную информацию нормативного характера о должном отношении человека к самому себе, другим, обществу, природе, миру в целом. Без интерпретации, раскодирования этой информации духовные ценности не могут восприниматься и выполнять свои функции. Из сказанного следует, что рациональность выступает в качестве необходимой информационной основы, составляющей духовности.

Природу рациональности характеризуют не только знания как результат ее функционирования, но и не в меньшей степени специфический способ их получения, для которого, как уже отмечалось здесь, присущи определенные правила, каноны. Вследствие этого и знания, полученные рациональным способом, обладают определенными качественными особенностями - объективностью, достоверностью и др. Все это явственно обнаруживается при сопоставлении рациональности с таким противоположным ей способом освоения мира как иррациональность.

Иррациональность всегда в той или иной мере и в различных формах присутствовала и присутствует в любой культуре. Но правомерно ли на этом основании рассматривать ее в качестве необходимого наряду с рациональностью способа освоения мира человеком? В настоящее время все более широкого распространяется принявшая под влиянием постмодернизма характер моды тенденция ставить в один ряд с религией, оккультизмом, эзотерикой и научную рациональность. Так, например, один из авторитетнейших постмодернистов Ф. Лиотар, исходя из идеи «гетероморфной природы языковых игр», считает, что «игра науки (языковая игра - авторы), таким образом, уравнивается с другими играми... В постмодернизме открыта дорога для важнейшего течения: наука играет свою собственную игру; она не способна легитимировать иные языковые игры» [11, с.31].

О несостоятельности уравнивания рациональности и иррациональ- 
ности со всей определенностью свидетельствуют как история культуры, так и повседневные жизненные реалии. Так, вряд ли можно рассматривать как случайность то, что в истории человечества не существовало и не существует такой развитой культуры, которая была бы основана на иррациональности. Даже в культурах Востока, где иррационализм достаточно распространен, определяющей роли он не играет, что вполне закономерно: построенная на фундаменте иррациональности культура давала бы неадекватное (иллюзорное, превратное) представление о человеке, мире и характере их взаимоотношений. Выработанные на такой основе знания, нормы и ценности не могли бы выполнять главной своей функции - быть способом, средством и формой успешного материального и духовного освоения мира человеком, его самореализации, развития и совершенствования.

В качестве примера уравнивания в человеке и его бытии рационального и иррационального может рассматриваться позиция французского философа Э. Морена: «Нам попросту необходимо признать, - пишет он, - что homo sapiens est homo demens (,человек разумный есть человек неразумный“). Человек по своей сути - мудрец-безумец. . . Речь идет теперь о том, чтобы спросить себя, осуществляется ли прогресс сложности, изобретательности, разумности и социальности вопреки ошибкам, беспорядку и фантазии, заодно с ними или же благодаря им. И мы ответим так: одновременно- $-и$ благодаря, и заодно, u вопреки; ибо правильный ответ может быть только сложным» [13, с. 107, 109]. То, что в общественном процессе присутствует все перечисленное Э. Мореном, сомнений не вызывает. Но означает ли это, что истина и заблуждение, порядок и беспорядок, творческая фантазия и бесплодные иллюзии играют в общественном развитии одинаковую роль? Вряд ли, ведь в этом случае не могло бы быть общественного прогресса как поступательного движения.

Еще менее обоснованным представляется вывод Мудрагей Н.С. о том, что иррациональность самодостаточна в бытии и познании, а преобладание рациональности в философии, по мнению автора, вплоть до начала XIX века является свидетельством несовершенства человеческой мысли [8, т. 1]. Думается, что, напротив, названный факт заслуживает прямо противоположной оценки: он свидетельствует о здоровьи и творческой мощи человеческого духа и созданной им культуры в эпоху прогрессивного развития западной цивилизации.

На основе иррациональности также складывается и существует соответствующий тип духовности, к которому относятся эзотерическая, мистическая и др. духовность. Насколько правомерно включать сю- 
да и религиозную духовность? Исходя из томистской идеи гармонии веры и разума, некоторые религиозные мыслители и богословы утверждают, что религиозное сознание - это по своей сути рациональное сознание. Так, по мнению В.И. Кураева и А.В. Кураева, религиозное сознание представляет собой особый, высший тип рациональности «сверхрациональность» или «трансрациональность» [8, т. 1]. Нам представляется, что для такого вывода нет достаточных оснований. Констатируя противоречивость религиозного сознания, невозможно отрицать, что исходной и высшей реальностью для него является сверхъестественное начало. Это влечет за собой абсолютное доминирование в нем веры, мистического вопреки декларируемому принципу гармонии веры и человеческого разума. Следовательно, вполне правомерно рассматривать религиозное сознание как особый тип иррациональности, а религиозную духовность как специфический тип иррациональной духовности.

Если характеризовать сущность иррациональной духовности, то ее, по нашему мнению, следует отнести к квазидуховности [14]. Как и рациональная духовность, она тоже выполняет в культуре функцию одухотворения человеческого бытия. В обоих типах духовности в качестве основополагающих выступают многие общие ценности - добро, любовь, истина, красота и др. Однако интерпретация этих ценностей, путей и способов их воплощения в жизнь существенно различаются. Иррационализм, как уже упоминалось, вносит во все перечисленное иллюзорный или превратный смысл. Поэтому влияние иррациональных духовных ценностей на жизнь человека имеет весьма противоречивые, по преимуществу негативные последствия.

Таким образом, существуют все основания утверждать, что именно рациональность является необходимой информационной основой подлинной духовности. Однако к этому аспекту не сводится их взаимосвязь. Существует, по крайней мере, еще одна, не менее важная функция, которую выполняет рациональность в отношении духовности и в целом в культуре-рефлексивная, поскольку, как верно заметил Г. Гадамер, «разум является всеобей формой осуществления рефлексии. .., он не ограничен областью целесообразности» $[5$, с. 634].

Значимость рефлексивной функции рациональности по отношению к духовности невозможно переоценить. Она обусловлена прежде всего тем, что рефлективность является атрибутом духовности, необходимым условием ее становления и способом бытия. Только в процессе рефлексии могут сформироваться, а затем и развиваться, совершенствоваться духовные потребности и интересы, чувства и переживания 
и, еще в большей степени, - категории духовности, ее высшие ценности. Особенно явно это обнаруживается, когда речь идет не о закрытой, некритически-оптимистической рациональности, ограниченной целесообразностью, а о критически-рефлексивной. Только благодаря последней индивид способен вырабатывать подлинные духовные жизненные ценности, критически их осмысливать и переосмысливать.

Как ни велика для духовности роль рациональности, не следует недооценивать в данном отношении нерациональную сферу духовного мира индивида, представленную чувствами, эмоциями и переживаниями. Безусловно, роль и место названной сферы и рациональности в становлении и развитии духовности различны. Однако принципиально важно, на наш взгляд, не истолковывать это различие как противоположность, отдавая абсолютный приоритет одному из начал и факторов развития духовности, как это делается, например, в следующем суждении: «именно способность к определенным переживаниям, а не интеллектуальные и физические качества указывает на степень духовного развития личности» [1, с. 153]. Само собой разумеется, что физические качества индивида здесь ни при чем, но вот, что касается роли для характеристики духовности личности ее интеллектуальных качеств, - здесь с Л.В. Баевой трудно согласиться.

Верное жизненное наблюдение, что «весьма эрудированные люди нередко духовно бедны», вряд ли правомерно расценивать как подтверждение вывода: «показателем духовности бытия человека является эмоциональная окрашенность (выделено нами - авторы) и личная заинтересованность его соучастия в жизни других людей и мира в целом $[7$, с.60]. Ведь «эмоциональная окрашенность» и неравнодушие в отношении к другим и миру в целом может быть вызвана различными целями и мотивами; в том числе и весьма далекими от духовности или даже противоположными ей. Поэтому, размышляя о характере связи духовности индивида со сферой рационального и нерационального в его внутреннем мире, по-видимому, разумнее говорить не о противоположности, а о специфичности их роли в этом.

Нравственно-гуманистическая интенция духовности, выражающая ее сущностную определенность, делает невозможной ее без таких качеств личности, как душевная бескорыстная отзывчивость, способность к искреннему сочувствию и глубокому сопереживанию, состраданию и любви. В этом смысле, действительно, «переживание выступает основанием (уточним: чувственно-эмоциональним основанием - авторы) духовности». Но если согласиться, что при этом принципиальное «значение имеет не только «факт переживания», но и 
его качество» $[1$, с.153], то первостепенную значимость приобретает ценностная направленность последнего. Направленность же духовных чувств, эмоций и переживаний личности обусловливается, «задается» системой ее ценностных ориентаций, а в конечном счете, основополагающими смысложизненными духовными ценностями. Такова органичная взаимосвязь рационального и нерационального с духовностью личности.

Названная связь возникает, поддерживается и воспроизводится в процессе повседневной жизнедеятельности личности, когда она, движимая своими духовными потребностями и переживаниями, стремится осуществить соответствующие ценностные ориентации. В этом смысле трудно согласиться с позицией, отрывающей духовность индивида от эмпирических реалий его повседневной жизни и противопоставляющей их: «Духовная жизнь не рождается из эмпирического развития, не создается им, а только опосредуется... Духовные структуры личности возникают на основе ценностно-смысловых переживаний. Их особенность состоит в том, что они практически независимы (подчеркнуто нами - авторы) от сферы эмпирического», утверждает В.Н. Волков [4, с. 121, 360].

Безусловно, духовность не может возникнуть самопроизвольно, «сама собой» в эмпирическом развитии индивида, но при одном принципиально важном условии: если индивид совсем не осваивает в процессе воспитания и образования духовную культуру. Надо ли говорить, что такое «эмпирическое развитие» индивида как личности является, за редкими, аномальными исключениями, искусственно созданной лишенной смысла абстракцией. Поэтому и не может духовность быть «практически независимой от сферы эмпирического», сферы, где она только и может сформироваться и, самоосуществляясь, развиваться и совершенствоваться.

До сих пор речь шла о том, что без рациональности (особенно критически-рефлексивного типа) подлинная духовность невозможна. Но правомерно ли аналогичное утверждение о духовности в ее отношении к рациональности? Мы полагаем, что да, хотя, на первый взгляд, так может и не показаться. Если подойти к рациональности с формально-логической стороны, то может показаться, что она осуществляется и без каких бы то ни было ценностей, включая и духовные. Но насколько обоснован такой подход, когда речь идет о рациональности в целом? Ведь она при этом рассматривается лишь с одной, условно говоря, технологической стороны, как мыслительная деятельность вообще, которая лежит и в основе иррациональности. Если же раци- 
ональность берется не в «урезанном» виде, а в полном своем объеме и качественной определенности, как способ освоения мира человеком, то она не может успешно осуществлять своих функций в культуре без духовности.

Духовные ценности выступают для человека в процессе рациональной практической или познавательной деятельности в качестве исходных (мировоззренческих, методологических, аксиологических) ориентиров, норм и установок, задающих ракурс и горизонт восприятия и преобразования действительности. Поэтому принципиально важное значение имеет характер функционирующих (а не декларируемых!) в обществе духовных ценностей. Если это не подлинные, псевдодуховные ценности, что все более характерно для современной культуры, то и направляемая ими рациональность дает искаженную или ложную информацию о человеке и действительности. Аналогичная метаморфоза происходит и в том случае, если рациональность используется как инструмент, способ обоснования псевдоценностей, создавая им имидж подлинных и современных.

Такая ценностная ориентация рациональности не проходит бесследно и для нее самой: теряя свои сущностные признаки (например, «пафос адекватности» действительности) и одновременно эклектически вбирая в себя то, что противоречит ее природе (например, эзотерику), рациональность постепенно перерождается. Потеря идентичности - реальная и весьма актуальная для современной рациональности, как и духовности, проблема и одновременно свидетельство их нынешнего кризиса.

Выражением названного кризиса является нарастание отнюдь не диалектической противоречивости во взаимоотношениях между рациональностью и духовностью. Потребительство как жизненная философия и психология с присущей ему прагматической ориентацией на успех как высшую ценность и цель в условиях гипердинамизма повседневных реалий обусловливает все большую рационалистичность поведения индивида. Но это отнюдь не критически-рефлексивная рациональность: система духовных ценностей индивида, его жизненный уклад и культурно-информационное пространство, в котором он пребывает - все это не способствует выработке рациональности данного типа. Однако это и не оптимистическая рациональность, ибо ситуация отчуждения, неустойчивости и неуверенности не только в жизненной перспективе, но и в ближайшем будущем не является благоприятной почвой для оптимистического мировосприятия и мироощущения. Учитывая сказанное, рациональность, характерную для обыденного созна- 
ния человека современной культуры, можно обозначить как некритически-прагматическую.

Основной функцией некритически-прагматической рациональности является вписывание индивида в непрерывно, неожиданно и независимо от него изменяющуюся жизненную ситуацию. Ориентация рациональности на ситуативность и утилитарную прагматичность неизбежно входит в противоречие с духовностью, устойчивые, общезначимые и непрагматичные ценности которой превращаются для индивида в объективное препятствие на пути к достижению им своих повседневных целей. Известный британский социолог З. Бауман эту ситуацию, характерную для современного западного общества, описывает следующим образом: «В калейдоскопическом же мире перетасовываемых ценностей, изменяющихся маршрутов и расплывающихся рамок свобода маневра поднимается до ранга высшей ценности - метаценности. . . Рациональное поведение в таком мире требует, чтобы возможностей выбора было как можно больше и чтобы они всегда были открыты» [3, с. 186-187].

Очевидно, что духовность и является одной из главных помех для реализации превратившейся для индивида в «метаценность» свободы ценностного маневра, закрывая противоречащие духовности пути выбора. Поэтому некритически-прагматическая рациональность и не может сочетаться с подлинной духовностью, быть ее информационной основой и способом обоснования. Разрешается названное противоречие в процессе перерождения духовности в квазидуховность, которая вполне сочетается с некритически-прагматической рациональностью.

Неизбежным следствием кризиса современной рациональности и духовности являются негативные изменения не только в них самих, и характере их взаимоотношений, но и в культуре, и в бытии человека. Отказ от высших, абсолютных, универсальных духовных ценностей, придававших индивидуальному (и социальному) бытию целостность, превращает его в дезинтегрированное и фрагментарное. Это порождает «ощущение ,разъединенного времени“, идущего от неожиданного эпизода к непредвиденному, и угрожающего способности человека составить из отдельных фрагментов целостное повествование» $[3$, с. LV] - собственную жизнь.

Столь радикальные, негативные по своему характеру изменения в духовном мире и жизненных реалиях современного человека не могут не изменять и его самого: он все больше превращается в «дезориентированного, ограниченного, беспомощного» $[3$, с. XIV] с неразвитыми духовными интересами, унифицированными, стандартными ценностя- 
ми и некритически-прагматической рациональностью, - человека, который «смотрит на жизнь сквозь призму бухгалтерского баланса» $[6$, c. 108].

\section{1 Литература}

[1] Баева Л.В. Ценностные основания индивидуального бытия: опыт экзистенциальной аксиологии. - М., 2003.

[2] Барулин B.C. Основы социально-философской антропологии. M., 2002.

[3] Бауман З. Индивидуализированное общество. - М., 2002.

[4] Волков В.Н. Онтология Личности. - Иваново, 2001.

[5] Гадамер Г.-Г. Истина и метод. - М., 1988.

[6] Геллнер Э. Условия свободы. Гражданское общество и его исторические соперники. - М., 1995.

[7] Иконникова Н.И. Бытие человека: трансцендентные и экзистенциальные измерения. - М., 2003.

[8] Исторические типы рациональности. В двух томах.-M., 1995.

[9] Келле В.Ж. Интеллектуальная и духовная составляющие культуры // Вопросы философии. - 2005. - № 10.

[10] Козловски П. Культура постмодерна. - М., 1997.

[11] Лиотар Ж..Ф. Ситуация постмодерна // Философская и социологическая мысль. - 1995. - № 5-6.

[12] Лотман М.Ю. Семиотика культуры //Экология и жизнь. 2003. 一 № 6(35).

[13] Морен Э. Утраченная парадигма: природа человека // Философская и социологическая мысль. - 1995. - № 5-6.

[14] Писчиков B.C., Холин М.М. Квазидуховность как превращенная форма духовности // Актуальні проблеми духовності. Вип. 7.Кривий Ріг, 2006.

[15] Швырев В.С. Рациональность как ценность культуры. Традиция и современность. - М., 2003. 